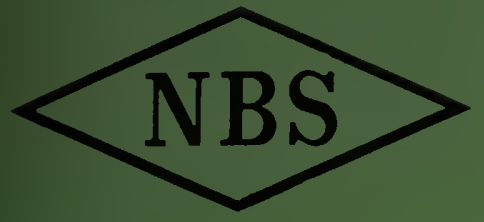

PB 161622

Eechnical Note

no. 121

Boulder Laboratories

\title{
PRECISION CALIBRATION OF RF VACUUM TUBE VOLTMETERS
}

\author{
BY \\ L. F. BEHRENT
}

U. S. DEPARTMENT OF COMMERCE NATIONAL BUREAU OF STANDARDS 


\section{THE NATIONAL BUREAU OF STANDARDS}

\section{Functions and Activities}

The functions of the National Bureau of Standards are set forth in the Act of Congress, March 3, 1901, as amended by Congress in Public Law 619, 1950. These include the development and maintenance of the national standards of measurement and the provision of means and methods for making measurements consistent with these standards; the determination of physical constants and properties of materials; the development of methods and instruments for testing materials, devices, and structures; advisory services to government agencies on scientific and technical problems; invention and development of devices to serve special needs of the Government; and the development of standard practices, codes, and specifications. The work includes basic and applied research, development, engineering, instrumentation, testing, evaluation, calibration services, and various consultation and information services. Research projects are also performed for other government agencies when the work relates to and supplements the basic program of the Bureau or when the Bureau's unique competence is required. The scope of activities is suggested by the listing of divisions and sections on the inside of the back cover.

\section{Publications}

The results of the Bureau's research are published either in the Bureau's own series of publications or in the journals of professional and scientific societies. The Bureau itself publishes three periodicals available from the Government Printing Office: The Journal of Research, published in four separate sections, presents complete scientific and technical papers; the Technical News Bulletin presents summary and preliminary reports on work in progress; and Basic Radio Propagation Predictions provides data for determining the best frequencies to use for radio communications throughout the world. There are also five series of nonperiodical publications: Monographs, Applied Mathematics Series, Handbooks, Miscellaneous Publications, and Technical Notes.

A complete listing of the Bureau's publications can be found in National Bureau of Standards Circular 460, Publications of the National Bureau of Standards, 1901 to June 1947 (\$1.25), and the Supplement to National Bureau of Standards Circular 460, July 1947 to June 1957 (\$1.50), and Miscellaneous Publication 240, July 1957 to June 1960 (Includes Titles of Papers Published in Outside Journals 1950 to 1959) (\$2.25); available from the Superintendent of Documents, Government Printing Office, Washington 25, D. C. 


\title{
NATIONAL BUREAU OF STANDARDS Eechnical Mote
}

121

DECEMBER 1961

\author{
PRECISION CALIBRATION
}

OF

RF VACUUM TUBE VOLTMETERS

by

L. F. Behrent

NBS Technical Notes are designed to supplement the Bureau's regular publications program. They provide a means for making available scientific data that are of transient or limited interest. Technical Notes may be listed or referred to in the open literature. They are for sale by the Office of Technical Services, U. S. Department of Commerce, Washington 25, D. C.

DISTRIBUTED BY

UNITED STATES DEPARTMENT OF COMMERCE OFFICE OF TECHNICAL SERVICES

WASHINGTON 25, D. C.

Price $\$ .50$ 



\section{Page}

ABSTRACT $\quad$ ii

1. INTRODUCTION 1

2. CALIBRATION 1

2. 1 Accuracy 2

2.2 Working Standards 2

2. 3 Procedure 2

2. 4 Precautions 4

3. CONCLUSIONS 6

4. REFERENCES 8

5. FIGURES 9

la RF calibration of vacuum tube voltmeter with an $R F$ Micropotentiometer.

Ib D-C calibration of the RF Micropotentiometer.

2. Calibrating a vacuum tube voltmeter against a thermal converter as working standard.

3. Placement of an external shielding braid over the $r f$ probe of a VTVM and the cable connecting the probe output to the VTVM.

4. Calibrating a VTVM at low frequencies against an RF Micropotentiometer at millivolt levels. "A" is an adapter from type $\mathrm{N}$ to terminal posts.

5. Calibrating a VTVM against an AT voltmeter using commercial type $\mathrm{N}$ connectors 

PRECISION CALIBRATION OF RF VACUUM TUBE VOLTMETERS

by

L. F. Behrent

\section{ABSTRACT}

Before any rf vacuum tube voltmeter is to be calibrated, it should be tested for several weeks to determine how well it may retain its calibration. In this way effort lost in trying to calibrate it to an accuracy beyond its inherent capabilities can be avoided. AT voltmeters, Thermal Converters and RF Micropotentiometers as working standards provide simple, accurate and yet rapid means'for calibrating vacuum tube voltmeters. 



\title{
PRECISION CALIBRATION OF RF VACUUM TUBE VOLTMETERS
}

\author{
by \\ L. F。Behrent \\ 1.00 Introduction
}

In describing calibration procedures for $r f$ vacuum tube voltmeters, the discussion will be limited to voltmeters having an unbalanced, two-terminal input with one side a.t ground potential. The rf voltages used in maling the calibrations will be confined to $\mathrm{cw}$, essentially sinusoidal, voltages.

Vacuum-tube voltmeters are not inherently stable. From a survey conducted at INBS some time ago in which the calibrations of several different types of vacuum-tube voltmeters were checked against the primary standards of rf voltage, changes in calibration in some cases as high as 10-20 percent were observed over a period of only a few months. Therefore, before any vacuum-tube voltmeter is calibrated, it should be checked against a reliable standard for a period of several weeks to determine its probable stability. The calibration procedure used should give an accuracy commensurate with the capabilities of the voltmeter under test.

\subsection{Calibration}

Calibration activities can appropriately be divided into levels or echelons according to the range of accuracies and the purposes they serve in the calibrations structure. A practical breakdown has been proposed $1 /$ in which three echelons are set up. In Echelon I are included the Primary and Secondary standards maintained by the NBS. Echelon II includes the working standards maintained by standards laboratories in industry, other branches of government and universities These standards are traceable to the NBS and are used in calibrating the working standards of Echelon III. The third level, Echelon III, contains the standards used in calibrating the instruments used by the consumer - for example, production line test departments and those engaged in the repair and calibration of instruments. Vacuum-tube voltmeters generally should be calibrated at the third echelon because they lack the stability to warrant the extra effort and expense involved in higher order accuracy calibrations. 
$\underline{2.10 \text { Accuracy }}$

The accuracies which may be expected depend upon both rf voltage level and frequency. Below $10 \mathrm{Mc}$, accuracies of $0.5-2$ percent can be obtained, while $10-25$ percent can be expected between 100 and $1000 \mathrm{Mc}$. So it is evident that at lower frequencies, even in Echelon III, accuracies better than needed for VTVM calibrations are possible.

\section{20 Working Standards}

Suitable working standards which may be used to calibrate VTVM's are AT voltmeters, Micropotentiometers, and thermal converters $2,3,4 /$ - the Micropotentiometer for calibrating millivolt rf voltage levels at all frequencies, thermal converters for higher voltages up to 30 or $100 \mathrm{Mc}$, and $\mathrm{AT}$ voltmeters to complete the coverage to $1000 \mathrm{Mc}$.

\subsection{Procedure}

In general, to calibrate a VTVM, the working standard and the voltmeter to be tested are connected in parallel, and with rf voltage applied to both, the level is adjusted to give the desired indication of the test instrument. The actual magnitude of the rf voltage applied is then determined from the calibrated indication of the working standard. The detailed steps will depend on the working standard being used.

For rf voltage levels of 1-100 mv the RF Micropotentiometer is the best worlking standard to use at the present time. Table I shows a typical selection of such standards to give complete voltag.e coverage within this range. The basic circuit illustrating the use of RF Micropotentiometers in VTVM calibration is shown in Figure 1 a.

Table I

Typical Selection of RF Micropotentiometers for MV Levels

Thermoelement Resistance Element,

rating, ma

100

25 ohms

1.0

1.0

1.0
Standardized $\mathrm{mv}$

\begin{tabular}{r} 
output \\
\hline $20-100$ \\
$5-25$ \\
$1-5$
\end{tabular}


The rf portion of the calibration procedure is as follows:

1) With the rf input terminals of the VTVM connected to the working standard's output terminals, energize the voltmeter according to the manufacturer's recommended procedure. Allow a fifteen minute warm-up period before beginning the tests, unless the manufacturer or user specifies a longer one.

2) Make meter zero corrections and/or any other adjustments specified by the user or manufacturer. (Many VTVM's capable of measuring millivolts have a suppressed zero, in which case the zero adjustment will be omitted.)

3) Apply a sinusoidal, cw, rf voltage to give the desired test voltmeter indication, and record the working standard's millivoltmeter indication.

4) Remove the rf signal, and, if the voltmeter does not have a suppressed zero, recheck the zero. If the zero requires resetting the validity of the rf calibration is doubtful. The data for that measurement should be discarded and the test repeated.

For each point on the meter of the VTVM to be calibrated at least five independent $r f$ measurements with the working standard should be made.

There are two ways in which the correction for rf error in the RF Micropotentiometer may have been expressed in the higher echelon calibration data. It might have been expressed as a percentage by which, for a given current in the resistance element, the rf voltage output was greater or less than the d-c calibration value at each frequency. Or, for a given current level in the resistance, the actual output at dc and each radio frequency may have been given. In either case it is necessary to use dc to calibrate the thermoelement monitor ing the current into the resistance element as shown in Figure $1 \mathrm{~b}$. This d-c calibration may be made after each measurement, for best accuracy, or one complete calibration can be obtained and plotted in graph form so that $d-c$ data for individual rf measurement points can be read from the graph. For such a graph, some 20 - 30 points of $d-c$ thermocouple millivolt output versus $d-c$ microvolt output across the resistance element as measured with a precision $d-c$ measuring potentiometer must be plotted. 
Where a d-c calibration is made immediately following an rf measurement, enough $d-c$ current is applied to the RF Micropotentiom -eter to reproduce the millivoltmeter indication obtained during the $r f$ measurement, and the $d-c$ output in millivolts is measured. The circuit of Figure $1 \mathrm{~b}$ applies to both procudures. Having completed the d-c calibration and having the $r f$ to $d-c$ correction, the actual $r f$ voltage output can be accurately calculated.

For rf voltage levels above 0.1 volt at frequencies of $100 \mathrm{Mc}$ and less, thermal converters are suitable working standards. Figure 2 presents the rather simple circuit arrangement. The test voltmeter and the working standard are connected in parallel and to an rf source through appropriate filters.

The calibration procedure contains very few steps. After the preliminary steps of allowing an adequate "warm-up" period to stabilize the VTVM, and the checking and adjustment of voltmeter zeros, only two steps remain. Apply sufficient $r$ voltage to produce the desired meter indication on the VTVM and record the indication of the working standard.

Upon completion of the test, remove the rf voltage and recheck zero settings. As before, any zero error renders the rf test invalid and the measurement must be repeated.

Above $100 \mathrm{Mc}$, a satisfactory working standard is the AT voltmeter. The circuit arrangement of Figure 2 applies here, too, except that where capacitive $\mathrm{AT}$ voltmeters are used a frequency meter must be added to permit checking and adjusting the $r f$ source to the same frequencies at which the working standard was calibrated. Except for several precautions which will be discussed in the following text, the procedure outlined for thermal converters applies here also.

\section{40 Precautions}

While VTVM's are not stable, as was pointed out before, following the precautions outlined below will help to realize the best perform ance of which they are capable.

1) Regulate the line voltage energizing the test instrument. The use of a good a-c regulator can help reduce voltmeter zero fluctuations may reduce calibration instability. The line voltage applied during 
tests should be recorded and reported so that subsequent users can adjust the line voltage to the same value at the sites where the meters are used for measurements. Failure to do this can introduce additional error.

2) Filter the rf voltage applied to the VTVM during calibration. Many vacuum-tube voltmeters are peak reading instruments. The presence of harmonics in the applied rf voltage can add several percent error to the measurements in such cases. The rf source should be filtered sufficiently to place the harmonics $50-60 \mathrm{db}$ below the fundamental.

3) Use only those rf sources whose rf output voltages have good amplitude stability during the short time it takes to make a measurement. For example: if an rf calibration measurement accuracy of \pm 5 percent is required, the output amplitude of the rf source should remain stable to within \pm 0.5 percent during the measurement.

4) Check the zero setting of the test meter both before and after each measurement. This point was discussed before but it cannot be overemphasized.

5) Check the entire $r f$ circuit, including rf source, connecting cables, the working standard and the test VTVM for rf leakage currents. It sometimes becomes necessary to place the rf source inside a double-screened box and to apply external shielding to connecting rf cables $5 /$. Quite frequently vacuum-tube voltmeters with highfrequency probes are not sufficiently shielded and it becomes necessary to place external shielding over the housing of the probe and the cable connecting the probe output to the voltmeter proper. See Figure 3.

6) Connect the test voltmeter's rf input terminals to the working standard with the shortest connections possible. Above a few megacycles banana pins and clip leads are not usable because of the error these lead lengths introduce. Even coaxial connections can introduce errors at very high frequencies because of the voltage standing wave in this length of transmission line between the applied rf voltage and the terminals of the test meter. To illustrate refer to Figure 4. Here an RF Micropotentiometer is the working 
standard. Its standardized rf output voltage is coupled to the input terminals of the VTVM through an adapter. This arrangement is sat:isfactory to about $5 \mathrm{Mc}$. Above this frequency, error will be caused by the lead lengths and discontinuities introduced by Adapter A. The accurately known rf voltage exists at the voltage reference plane $b-b$ (at the front face of the type $N$ output of the RF Micropotentiometer).

Another illustration is shown in Figure 5 where a vacuum-tube voltmeter probe is connected in parallel with an $A T$ voltmeter for highfrequency calibration. To illustrate the importance of short connections, standard type $N$ connectors and adapters are used. The plane in which the rf voltage is known at the working standard is $d-d$. With a type $\mathrm{N}$ connection on the test voltmeter probe, known rf voltage should be applied to the probe a.t the voltage reference plane $f-f$. At high radio frequencies, again because of the approximately $4.5 \mathrm{~cm}$ length of transmission line and the discontinuities in the connectors, the voltage at plane $f-f$ will differ from the voltage at $d-d$. At $100 \mathrm{Mc}$ a difference of several percent may occur. This is aggravated, too, because both the VTVM and the AT voltmeter are high impedances and the transmission line between them is not terminated in its characteristic impedance anywhere - consequently a very high standing wave ratio exists in the line section between them. Special $\mathrm{T}$ connections should be constructed to reduce the distance between the standard and the test meter as much as possible and still allow the rf voltage to be fed to them in parallel. In order that such special $T$ connectors may be usable over the widest possible frequency range, the length of the $\mathrm{T}$ between the voltmeter under test and the standard should be about one eighth of an inch.

\subsection{Conclusions}

The importance of knowing the capabilities of a VTVM before attempting calibration cannot be emphasized too strongly. There have been many instances where users, without prior investigation of voltmeter stability, have insisted upon 1 or 2 percent calibrations of VTVM's. In a matter of days, the calibration of the test voltmeter had already changed by a percentage greater than the specified accuracy and the calibration had to be terminated.

Because one cannot predict when VTVM may lose its calibration, it is recommended that any facility using VTVM's as voltage standards calibrate at least three to permit intercomparison. When one of them 
disagrees with the other two it should then be removed and recalibrated, after making suitable stability tests to determine whether or not it is still sufficiently stable to warrant recalibration.

Whatever means of connection is used for connecting the test meter to the working standard, the same $r f$ connection should be employed in making measurements or additional error due to connections will be introduced.

The working standards recommended here are capable of much greater accuracy than is required for these tests and may be used in both Echelon I and Echelon II. 


\section{REFERENCES}

1. IRE recommendation of standard practice for national correlation of measurement accuracy, Draft No. 5, subject to approval of the IRE Standards Committee.

2. Stable radiofrequency voltmeters, NBS Technical News Bulletin, 40, No. 2, 29-30 (Feb. 1956).

3. Selby, M. C., Accurate radio frequency microvoltages, AIEE Paper 53-22 (May 1953).

4. Hermach, F. L. \& E. S. Williams, Thermal voltage converters for accurate voltage measurements to 30 megacycles per second, AIEE Transactions, Pt. I (Communications and Electronics) (July 1960).

5. Behrent, L. F., Application of rf micropotentiometers for calibration of signal generators to $1000 \mathrm{Mc}$, NBS Technical Note No. 37, PB 151396 (Jan. 1960). 
5. FIGURES 


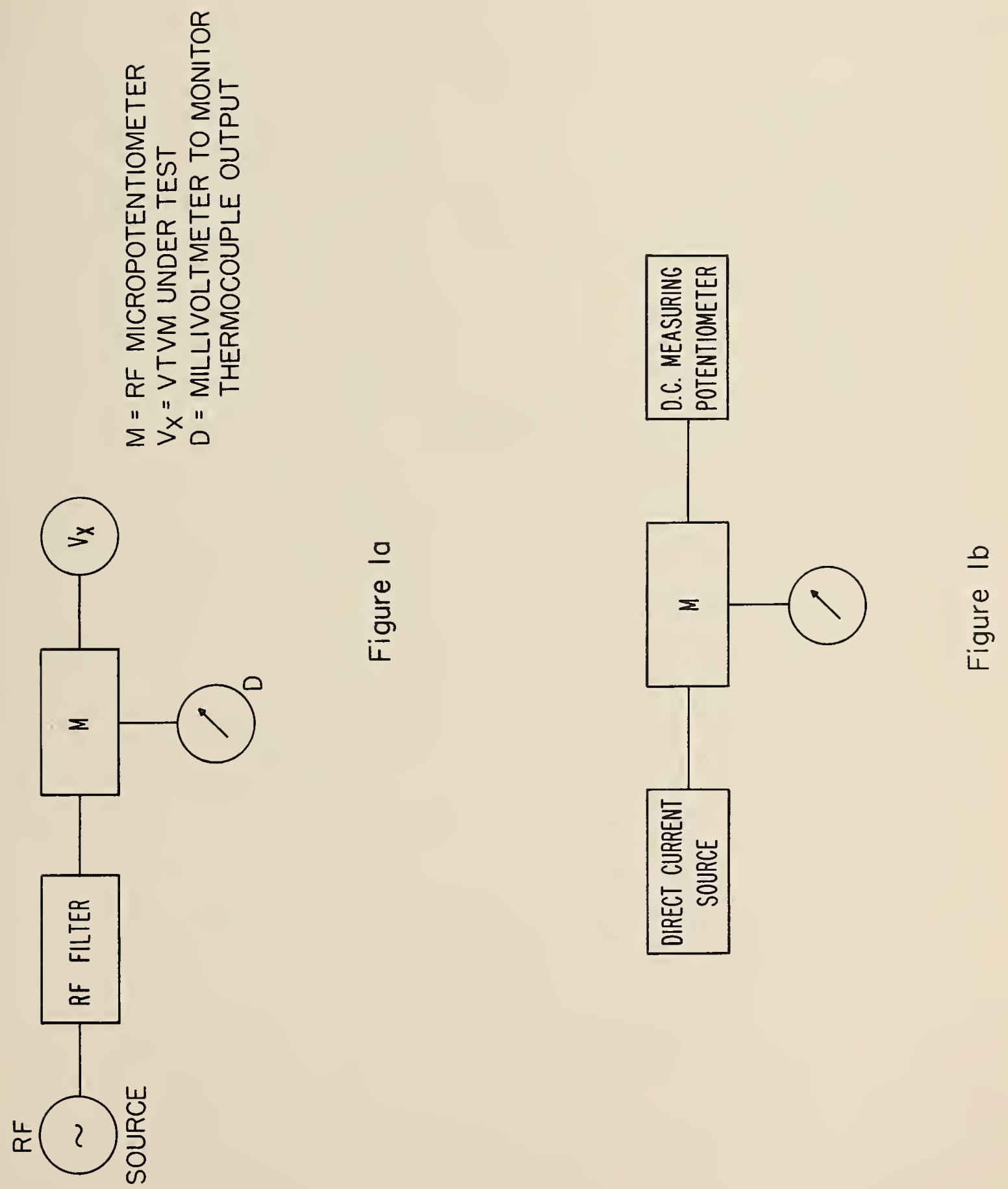



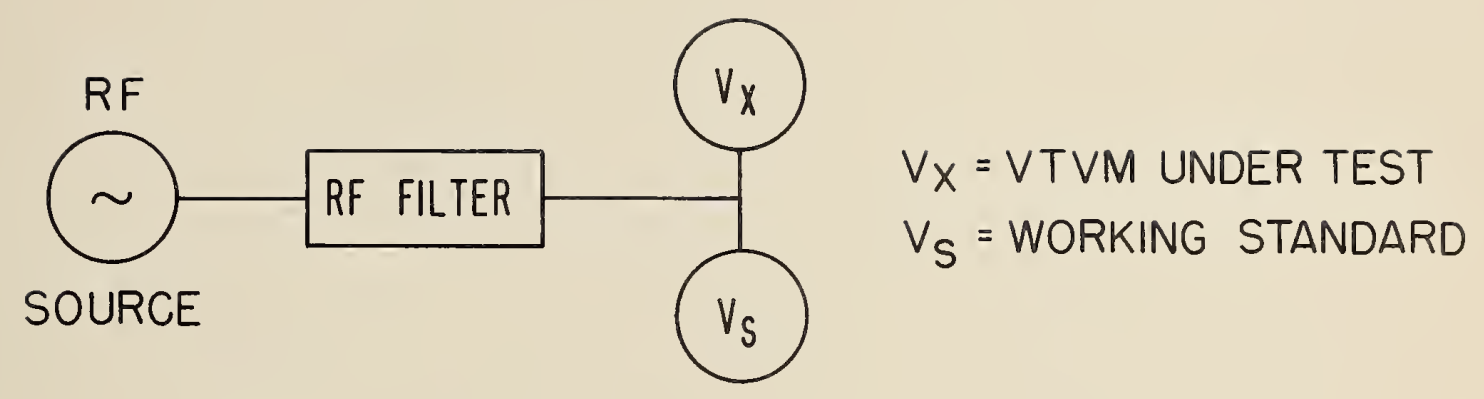

Figure 2

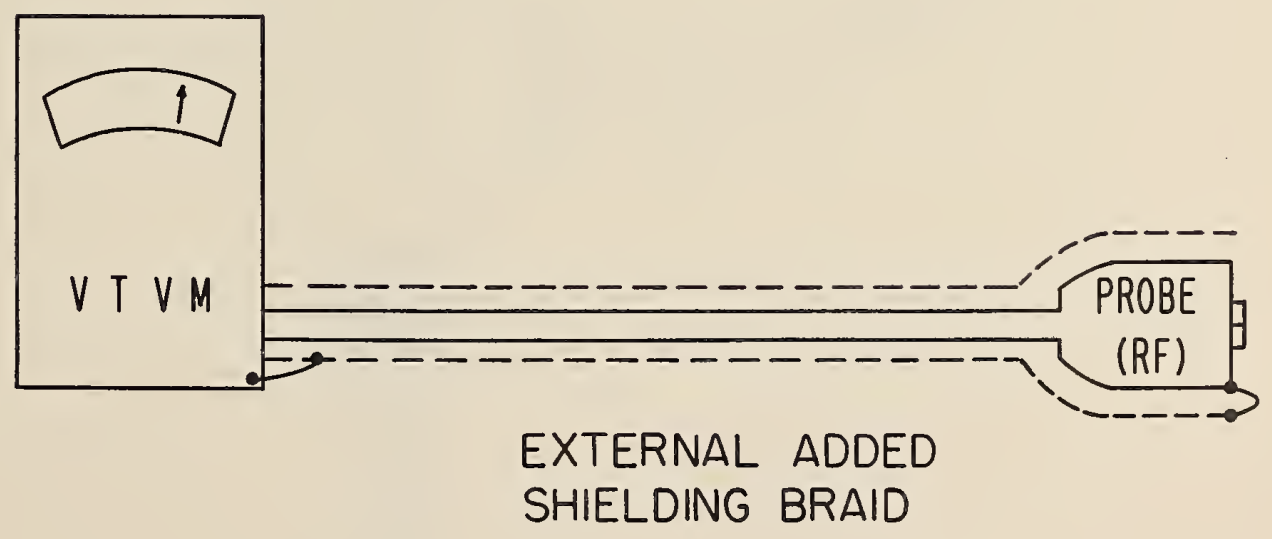

Figure 3 



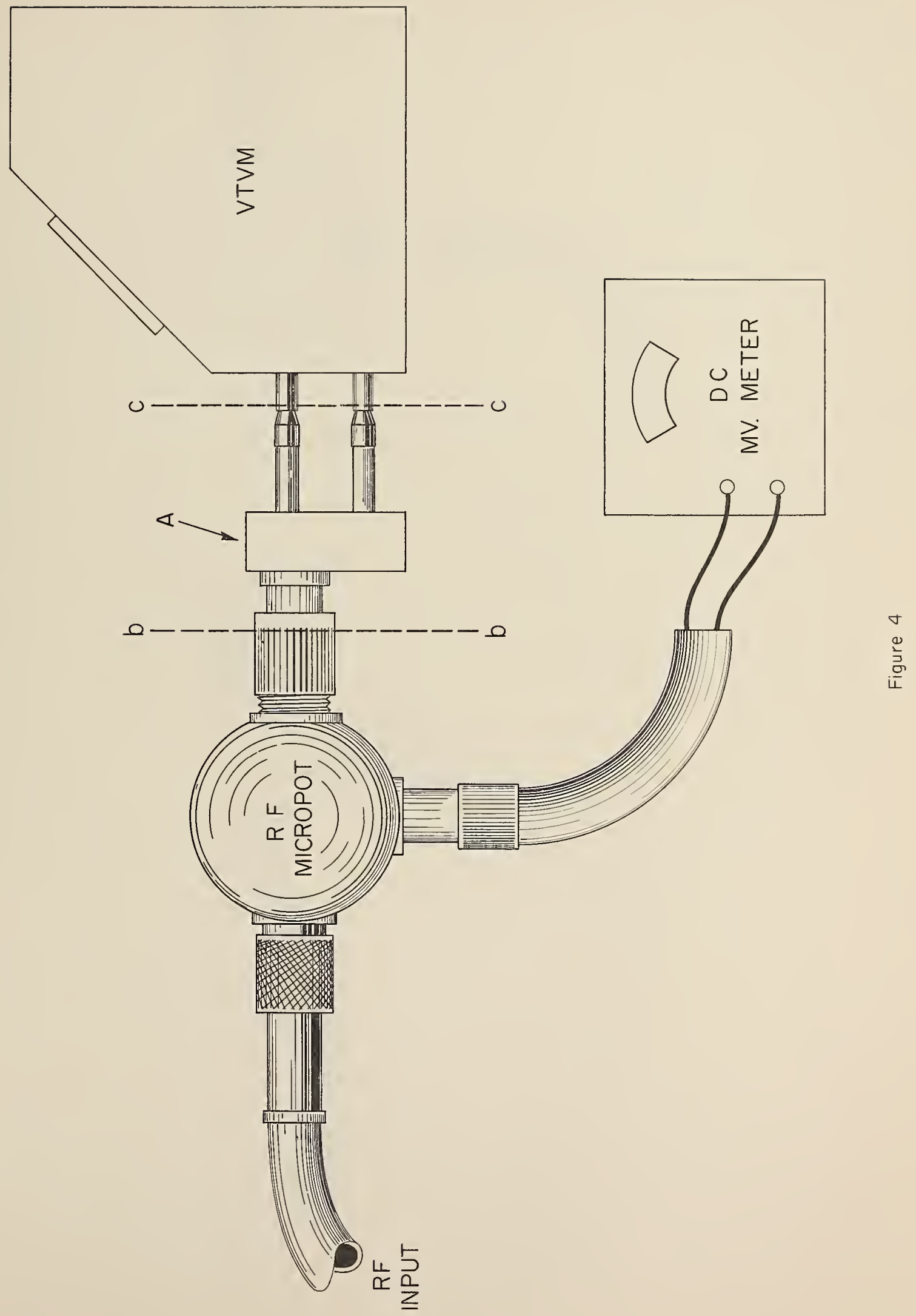





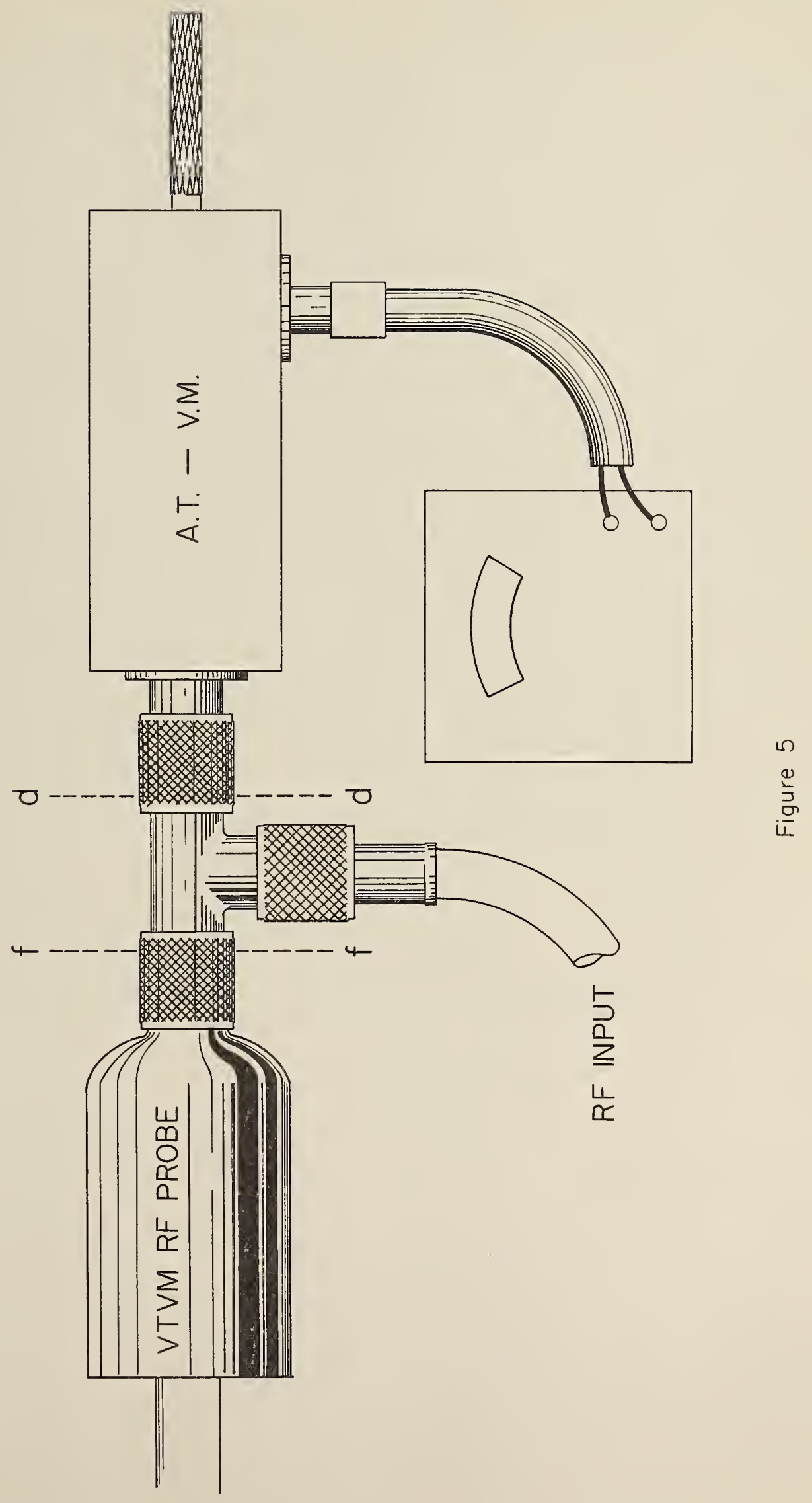



II. S. UEP AKTMENT OF COMMERGE

Luther H. Hodges, Secretary

NATIONAL PUREAU OF STANDARDS

A. V. Astin, Director

\section{THE NATIONAL BUREAU OF STANDARDS}

The scope of activities of the National Bureau of Standards at its major laboratories in Washington, D.C., and Boulder, Colorado, is suggested in the following listing of the divisionsand sections engaged in technical work. ln general, each section carries out specialized research, development, and engineering in the field indicated by its title. A brief description of the activities, and of the resultant publications, appears on the inside of the front caver.

\section{IVASIIINGTON, D.C.}

Electricity. Resistance and Reactance. Electrochemistry. Electrical Instruments. Magnetic Measurements. Dielectrics.

Metrology. Photometry and Colorimetry. Refractometry. Photographic Research. Length. Engineering Metrology. Mass and Scale. Volumetry and Densimetry.

Heat. Temperature Physics. Heat Mieasurements. Cryogenic Physics. Equation of State. Statistical Physics. Radiation Physics. X-ray. Radioactivity. Radiation Theory. High Energy Radiation. Radiological Equipment. Nucleonic Instrumentation. Neutron Physics.

Analytical and Inorganic Chemistry. Pure Substances. Spectrochemistry. Solution Chemistry. Standard Reference Materials. Applied Analytical Research.

Mechanics. Sound. Pressure and Vacuum. Fluid Mechanics. Engineering Mechanics. Rheology, Combustion Controls.

Organic and Fibrous Materials. Rubber. Textiles. Paper. Leather. Testing and Specifications. Polymer Structure. Plastics. Dental Research.

Metallurgy. Thermal Metallurgy. Chemical Metallurgy. Mechanical Metallurgy. Corrosion. Metal Physics. Electrolysis and Metal Deposition.

Mineral Products. Engineering Ceramics. Glass. Refractories. Enameled Metals. Crystal Growth. Physical Properties. Constitution and Microstructure.

Building Research. Structural Engineering. Fire Research. Mechanical Systems. Organic Building Materials. Codes and Safety Standards. Heat Transfer. Inorganic Building Materials.

Applied Mathematics. Numerical Analysis. Computation. Statistical Engineering. Mathematical Physics. Operations Research.

Data Processing Systems. Components and Techniques. Digital Circuitry. Digital Systems. Analog Systems. Applications Engineering.

Atomic Physics. Spectroscopy. Infrared Spectroscopy. Solid State Physics. Electron Physics. Atomic Physics. Instrumentation. Engineering Electronics. Electron Devices. Electronic Instrumentation. Mechanical Instruments. Basic Instrumentation.

Physical Chemistry. Thermochemistry. Surface Chemistry. Organic Chemistry. Molecular Spectroscopy. Molecular Kinetics. Mlass Spectrometry.

Office of Weights and Measures.

\section{BOULDER, COLO.}

Cryogenic Engineering. Cryogenic Equipment. Cryogenic Processes. Properties of Materials. Cryogenic Technical Services.

lonosphere Research and Propagation. Low Frequency and Very Low Frequency Research. Ionosphere Research. Prediction Services. Sun-Earth Relationships. Field Engineering. Radio Warning Services.

Radio Propagation Engineering. Data Reduction lnstrumentation. Radio Noise. Tropospheric Measurements. Tropospheric Analysis. Propagation-Terrain Effects. Radio-Meteorology. Lower Atmosphere Physics.

Radio Staniards. High Frequency Electrical Standards. Radio Broadcast Service. Radio and Microwave Materials. Atomic Frequency and Time Interval Standards. Electronic Calibration Center. Millimeter-Wave Research. Microwave Circuit Standards.

Radio Systems. High Frequency and Very High Frequency Research. Modulation Research. Antenna Research. Navigation Systems.

Upper Atmosphere and Space Physics. Upper Atmosphere and Plasma Physics. lonosphere and Exosphere Scatter. Airglow and Aurora. lonospheric Radio Astronomy. 


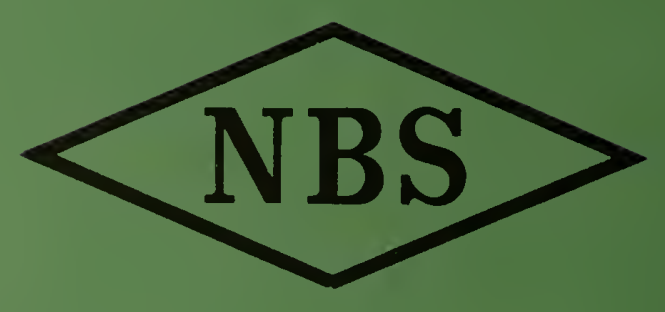

